\title{
Anthropometric Assessment of Nutritional Status in Pregnant Women in Different Trimesters Attending at the Antenatal Clinic of DMCH
}

\author{
*A Lutfa ${ }^{1}$, MB Hossain ${ }^{2}$, AMAA Awal ${ }^{3}$, A Nesa ${ }^{4}$
}

\author{
${ }^{1}$ Dr. Lutfa Akther, Program co-coordinator (Training), RHSTEP, Dhaka Medical College Hospital, Dhaka \\ ${ }^{2}$ Dr. Muhammad Belal Hossain, Department of Public Health, American International University-Bangladesh \\ ${ }^{3}$ Dr. A.A.M. Anisul Awwal, Director, (Training), National Institute of Population Research and Training, Bangladesh \\ ${ }^{4}$ Dr. Ayatun Nesa, Consultant, Clinical Pathology, BIRDEM General Hospital \\ *Corresponding Author
}

\begin{abstract}
Background: Adequate nutritional status of expectant mothers is essential for their health maintenance and good pregnancy outcome. To assess the anthropometric measurements of pregnant women.

Methodology: Cross sectional study, 245 pregnant women was included whom attended at antenatal clinic of Dhaka Medical College hospital. Main outcome measures: 38\% pregnant women were found with overweight or obese and $20 \%$ were found underweight that was related with chronic energy deficiency, vitamin deficiency and Iron deficiency anemia.

Result: A total of 245 women were in this study, the highest number $(48.16 \%)$ was found visited in the second trimester, $32.24 \%$ were in third and $19.5 \%$ in 1st trimester respectively. The mean age of women attending in this study was $23 \%$. It was surprising that our upcoming mother's did not have good height, around $60 \%$ were found less than five feet and $24 \%$ women were less than four feet eight inches, which indicated that a significant proportion of women might need to have surgical intervention during delivery. Not only the height, but also the weight of our respondents was found much poor and $16 \%$ of total attending women had weight below 40 kilogram.

Conclusion: Our study revealed that the majority of the women suffered from chronic energy deficiency which could be the potential factor for delivering malnourished babies. All pregnant women should be motivated to have an antenatal check up throughout the pregnancy, increase birth spacing to hold their proper nutritional status and encourage them to delivery their babies in hospital.
\end{abstract}

Key Words: Anthropometry, Trimester, Pregnant Women

\section{Introduction}

Nutrition is one of the most important factors influencing the quality of human life. Nutritional status is an important health indicator to assess a country's health status and morbidity pattern. Nutritional disorders are very frequent in women and involve a high risk of morbidity and mortality. Studies on nutritional status are very important in the women of childbearing age because of low to moderate prevalence of possible deficiencies. ${ }^{1}$ The relationship between nutritional status and health of mothers and newborn is well documented. ${ }^{2}$ Morbidity and mortality are inversely related to socio-economic status. ${ }^{3}$

Pregnant women, represent the most vulnerable to nutritional deprivation. Most vulnerable, because their

nutritional requirements are proportionally higher and the effects of malnutrition are severe and longlasting. ${ }^{4,5}$

AKMMC J 2015; 6(1): 20-24
Adequate nutritional status of expectant mothers is essential for their health and pregnancy outcomes. Due to increased nutritional requirements pregnancy is a critical period for meeting the body's demand for macro and micronutrients. Thus, anaemia and vitamin A deficiency (VAD) are highly prevalent nutrient deficiencies encountered in pregnant women, affecting 53.8 million $(55.8 \%)$ and $7.2 \%$ million $(6.8 \%)$ on a global scale, respectively. ${ }^{6,7}$ Both deficiencies have been shown to result in serious health consequences including increased morbidity and mortality of both mother $\&$ child. ${ }^{8}$

\section{Materials and Method}

This descriptive type of cross-sectional study was conducted among the pregnant women attending at the antenatal clinic of DMCH from January 2011 to April 2011. There was purposive selection of the study site as the study population was available at the site. 
AKMMC J $2015: 6(1)$

The sample size were calculated by using the formula, $n=\frac{z^{2} p q}{d^{2}}$

$\mathrm{n}=$ the desired sample size.

$\mathrm{z}=$ the standard normal deviate usually set at 1.96 , corresponds to the $95 \%$ confidence level.

$\mathrm{p}=$ the proportion in the target population estimate to have a particular characteristics and desire accuracy at $80 \%$

$\mathrm{q}=\mathrm{I}-\mathrm{P}=1-0.80=0.2$

$\mathrm{d}=$ degree of accuracy desired, usually set at 0.05 .

So the sample size is:

$$
\begin{aligned}
\mathrm{n} & =\frac{(1.96)^{2}(0.80)(0.2)}{(0.05)^{2}} \\
& =245
\end{aligned}
$$

There was purposive selection of sample size. Pretested semistructure questionnaire were used as data collection instruments.

- The anthropometric measurements to the subjects had to be considered, height, weight. Body weight was measured to the nearest $0.5 \mathrm{~kg}$, on a portable weighing scale. Standing height was measured with a wall mounted scale to the nearest $0.5 \mathrm{~kg}$, on a portable weighing scale. Standing height was measured with a wall-mounted scale to the nearest $0.5 \mathrm{~cm}$, with head in the Frankfurt horizontal plane,' while standing straight on a horizontal surface with the heels together the shoulders released, arms at the sides and without shoes. Height and weight were used to calculate Quetelet or Body Mass Index BMI [weight $(\mathrm{kg}) /$ height $\left(\mathrm{m}^{2}\right)$ ]. The classifications of BMI applied in this study were recommended by World Health Organization. ${ }^{9}$ BMI values of $<18.5 \mathrm{~kg} / \mathrm{m}^{2}$ and $\geq 25$ $\mathrm{kg} / \mathrm{m}^{2}$ represented thinners and overweight, respectively. An acceptable weight was considered to fall within these two extremes. In the case of pregnant women, BMI of $<19.8 \mathrm{~kg} / \mathrm{m}^{2}$ indicated and underweight individual, while BMI of $19.8-26 \mathrm{~kg} / \mathrm{m}^{2}$ was considered to be within the normal range. ${ }^{10}$

\section{Result}

Table 1: Age distribution of the patients

\begin{tabular}{lccc}
\hline $\begin{array}{c}\text { Age (in } \\
\text { years) }\end{array}$ & Frequency & Percent & Mean \pm SD \\
\hline$\leq 20$ & 59 & 24.1 & \\
$21-25$ & 108 & 44.1 & \\
$26-30$ & 64 & 26.12 & $23.32 \pm 4.16$ \\
$31-35$ & 9 & 3.7 & \\
$>35$ & 5 & 2.04 & \\
Total & $\mathbf{2 4 5}$ & $\mathbf{1 0 0 . 0}$ & \\
\hline
\end{tabular}

A Lutfa, MB Hossain, AMAA Awal

Table 1 shows the distribution of ages of patients attending at the antenatal clinic of $\mathrm{DMCH}$. The mean age of patients was about 23.32 years.

Table 2: Height of the respondent women

\begin{tabular}{cccc}
\hline Age(in years & Frequency & Percent & Mean \pm SD \\
\hline 20 & 59 & 24.1 & \\
$21-25$ & 108 & 44.1 & \\
$26-30$ & 64 & 26.12 & $23.32 \pm 4.16$ \\
$31-35$ & 9 & 3.7 & \\
$>35$ & 5 & 2.04 & \\
Total & $\mathbf{2 4 5}$ & $\mathbf{1 0 0 . 0}$ & \\
\hline
\end{tabular}

Table 2 shows frequency distribution of the height of the pregnant women who attended at the anti-natal clinic of DMCH. Proportion of women with optimum height (more than 5 feet) constituted about $40 \%$ of the total women which indicates that majority of the women (about 60\%) suffered from chronic energy deficiency as indicated by their low stature/ height.

Table 3: Weight of the pregnant women

\begin{tabular}{lrrr}
\hline $\begin{array}{l}\text { Weight } \\
(\mathrm{Kg})\end{array}$ & Frequency & Percent & Mean \pm SD \\
\hline$\leq 40$ & 40 & 16.3 & \\
$41-50$ & 109 & 44.5 & \\
$51-60$ & 76 & 31.0 & $49.26 \pm 8.21$ \\
$>60$ & 20 & 8.2 & \\
Total & $\mathbf{2 4 5}$ & $\mathbf{1 0 0 . 0}$ & \\
\hline
\end{tabular}

Table 3 shows the frequency distribution of weight of the patients under study. The findings reveal that majority of the pregnant women suffered from chronic energy deficiency (CED) as indicated by low weight even during pregnancy.

Table 4: Relationship between income and number of

\begin{tabular}{|c|c|c|c|c|c|c|}
\hline \multirow{2}{*}{$\begin{array}{c}\text { Monthly } \\
\text { income }\end{array}$} & \multirow{2}{*}{$\begin{array}{c}\text { No. and } \\
\%\end{array}$} & \multicolumn{4}{|c|}{ Number of children } & \multirow[t]{2}{*}{ Total } \\
\hline & & 1 & $2-3$ & $4-5$ & $>5$ & \\
\hline \multirow{2}{*}{$\begin{array}{r}3000- \\
<5000\end{array}$} & No. & 4 & 20 & 7 & 3 & 34 \\
\hline & $\%$ & 11.8 & 58.8 & 20.6 & 8.8 & 100 \\
\hline \multirow{2}{*}{$\begin{array}{c}5000-0 \\
<1000\end{array}$} & No. & 30 & 30 & 24 & 13 & 97 \\
\hline & $\%$ & 30.9 & 30.9 & 24.7 & 13.4 & 100 \\
\hline $10000-0$ & No. & 39 & 29 & 3 & 2 & 73 \\
\hline \multirow[t]{2}{*}{$<15000$} & $\%$ & 53.4 & 39.7 & 4.1 & 2.7 & 100 \\
\hline & No. & 20 & 20 & 1 & 0 & 41 \\
\hline$>1500$ & $\%$ & 48.8 & 48.8 & 2.4 & 0.0 & 100 \\
\hline \multirow[t]{2}{*}{ Total } & No. & 93 & 99 & 35 & 18 & 245 \\
\hline & $\%$ & 38.0 & 40.4 & 14.3 & 7.3 & 100 \\
\hline
\end{tabular}
children 
Table 4 shows the relationship between monthly income of the respondents and number of children. Table depicts that the number of children is highest among monthly income $3000-<5000$ taka. About $58.8 \%$ of the respondents monthly family income ranged 3000-5000 whole had 2-3 children and only $11.8 \%$ of them had one child. Whereas about $48.8 \%$ of the families had monthly income $>15000$ taka had less than three children. However, table clearly shows the reverse relationship between children number and family income, family those had higher number of children had low income and low children number had high income.

Table 5: Weight of the body in accordance to their period of gestation

\begin{tabular}{|c|c|c|c|c|c|c|c|}
\hline \multirow{2}{*}{$\begin{array}{l}\text { Weigh } \\
\text { t (Kg) }\end{array}$} & \multicolumn{2}{|c|}{$\begin{array}{c}1^{\mathrm{st}} \\
\text { trimester } \\
(\mathrm{n}=48)\end{array}$} & \multicolumn{2}{|c|}{$\begin{array}{c}2^{n d} \\
\text { trimester } \\
(\mathrm{n}=118)\end{array}$} & \multicolumn{2}{|c|}{ 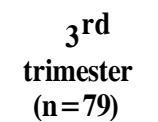 } & \multirow[t]{2}{*}{ Tota } \\
\hline & No & $\%$ & No & $\%$ & No & $\%$ & \\
\hline$\leq 40$ & 17 & 42.5 & 14 & 35.0 & 9 & 22.5 & 40 \\
\hline $41-50$ & 14 & $\begin{array}{c}12.8 \\
4\end{array}$ & 62 & $\begin{array}{c}56.8 \\
8\end{array}$ & 33 & $\begin{array}{c}30.2 \\
7\end{array}$ & $\begin{array}{c}10 \\
9\end{array}$ \\
\hline $51-60$ & 12 & $\begin{array}{c}15.7 \\
8\end{array}$ & 36 & $\begin{array}{c}47.3 \\
6\end{array}$ & 28 & $\begin{array}{c}36.8 \\
4\end{array}$ & 76 \\
\hline$>60$ & 5 & 25.0 & 6 & 30.0 & 9 & 45.0 & 20 \\
\hline
\end{tabular}

Table 5 shows the frequency distribution of weight of the pregnant women in their various stages of gestational period. In the $1^{\text {st }}$ trimester, there were only 48 women and $42.5 \%$ of them were less than $40 \mathrm{~kg}$ where as in the 2nd and 3rd trimester, number of the pregnant women with $>40 \mathrm{~kg}$ and $>50 \mathrm{~kg}$ increased significantly. The number of pregnant women in the $2^{\text {nd }}$ and $3^{\text {rd }}$ trimester was found 118 and 79 respectively, and body weight 40 $\mathrm{Kg}$ was more in 1st trimester than 2nd trimester and 3rd trimester which was $42.5 \%$ vs $35 \%$ and $22.5 \%$ but had no $35 \%$ vs $22.5 \%$ body weight in $40 \mathrm{Kg}$ of $3^{\text {rd }}$ trimester.

Table 6: BMI status of the pregnant women

\begin{tabular}{lccc}
\hline \multicolumn{1}{c}{ BMI } & Frequency & Percent \\
\hline $\begin{array}{l}\text { Under weight } \\
(<18.5)\end{array}$ & 49 & 20.00 \\
Normal $(18.5$ & $-24.9)$ & 103 & 42.04 \\
Over weight $(25$ & $-29.9)$ & 74 & 30.20 \\
Obese $(>30)$ & 19 & 7.76 \\
Total & $\mathbf{2 4 5}$ & $\mathbf{1 0 0 . 0}$ \\
\hline
\end{tabular}

Table 6 shows the frequency distribution of the pregnant women who attended the anti-natal clinic of DMCH. It is clear from the table that more than $38 \%$ of the women were either over weight or obese where as $42.04 \%$ were normal BMI. Maternal malnutrition is the primary and the basic cause of low birth weight around the world. It has been found that in Bangladesh, the incidence LBW is about $40 \%-50 \%$, and low/poor pregnancy weight gain on pre-pregnancy malnutrition resulted chronic energy deficiency during pregnancy, can be attributed as the major cause of LBW for most of the babies.

Table 7: BMI status at different trimester of pregnancy

\begin{tabular}{|c|c|c|c|c|c|c|c|}
\hline \multirow[t]{2}{*}{ BMI } & \multicolumn{2}{|c|}{$\begin{array}{c}1^{\text {st }} \\
\text { trimester } \\
(\mathrm{n}=48)\end{array}$} & \multicolumn{2}{|c|}{$\begin{array}{l}\underset{2 n d}{2 n d} \\
\text { trimester } \\
(\mathrm{n}=118)\end{array}$} & \multicolumn{2}{|c|}{$\begin{array}{c}3^{r d} \\
\text { trimester } \\
(n=79)\end{array}$} & \multirow[t]{2}{*}{ Total } \\
\hline & No. & $\%$ & No. & $\%$ & No. & $\%$ & \\
\hline $\begin{array}{l}\text { Under } \\
\text { weight } \\
(<18.5)\end{array}$ & 18 & $\begin{array}{c}36 . \\
73\end{array}$ & 17 & $\begin{array}{c}34 . \\
69\end{array}$ & 14 & $\begin{array}{c}28 . \\
57\end{array}$ & 49 \\
\hline $\begin{array}{l}\text { Normal } \\
(18.5 \\
24.9)\end{array}$ & 17 & $\begin{array}{c}16 . \\
05\end{array}$ & 58 & $\begin{array}{r}56 . \\
13\end{array}$ & 28 & $\begin{array}{r}27 . \\
18\end{array}$ & 103 \\
\hline $\begin{array}{l}\text { Over } \\
\text { weight } \\
(25-29.9)\end{array}$ & 7 & $\begin{array}{c}9.4 \\
5\end{array}$ & 35 & $\begin{array}{l}47 . \\
29\end{array}$ & 32 & $\begin{array}{r}43 . \\
24\end{array}$ & 74 \\
\hline $\begin{array}{l}\text { Obese } \\
(>30)\end{array}$ & 6 & $\begin{array}{c}31 . \\
57\end{array}$ & 8 & 42 & 5 & $\begin{array}{c}26 . \\
31\end{array}$ & 19 \\
\hline
\end{tabular}

Table 7 shows the relationships between the age of gestation and the BMI status. Out of 245 respondents, 49 of them were underweight although pregnancy and only 103 of them were normal in all the trimesters of pregnancy. However, it is surprising that $93(38 \%)$ of them were either over weight or obese which is much higher than the percentage of women who put on weight that is more than $7 \mathrm{~kg}$ and above.

It is important to note that in our country, about $35 \%$ $45 \%$ baby do born with low birth weight. It is also important to remember that the study was a cross sectional in design and thus, follow up of the individuals from 1st trimester was not possible in this study

Table 8: Distribution of patients in accordance to their pregnancy period

\begin{tabular}{ccc}
\hline Trimester & Frequency & Percent \\
\hline $1^{\text {st }}$ trimester & 48 & 19.59 \\
$2^{\text {nd }}$ trimester & 118 & 48.16 \\
3 rd trimester & 79 & 32.24 \\
Total & $\mathbf{2 4 5}$ & $\mathbf{1 0 0 . 0}$ \\
\hline
\end{tabular}


Table 8 shows the frequency of distribution pattern of the patients in accordance to their pregnancy stage.

Number of patients in $2^{\text {nd }}$ and $3^{\text {rd }}$ trimester was significantly higher than that of the 1st trimester, as almost all the pregnant women can recognize that they are pregnant about four months.

Table 9: Educational status of the pregnant women

\begin{tabular}{lcc}
\hline Educational status & Frequency & Percent \\
\hline Illiterate & 23 & 9.4 \\
Up to primary & 98 & 40.0 \\
Up to secondary & 74 & 30.2 \\
Up to higher secondary & 37 & 15.1 \\
Up to graduate & 13 & 5.3 \\
Total & $\mathbf{2 4 5}$ & $\mathbf{1 0 0 . 0}$ \\
\hline
\end{tabular}

Table 9 shows the frequency distribution of educational status, $9.4 \%$ were illiterate, $40 \%$ were completed primary, $30.2 \%$ were secondary, $15.1 \%$ were completed higher secondary and $5.3 \%$ were found graduate. Majority patients had lower level of education due to the economic constraint, early marriage and social barriers.

Table 10: Monthly family income of the respondents

\begin{tabular}{lccc}
\hline $\begin{array}{l}\text { Monthly } \\
\text { Income (Tk.) }\end{array}$ & Frequency & Percent & Mean \pm SD \\
\hline $3000<5000$ & 34 & 13.9 & \\
$5000-10000$ & 97 & 39.6 & \\
$>10000-15000$ & 73 & 29.8 & $12326 \pm 5541$ \\
$>15000$ & 41 & 16.7 & \\
Total & $\mathbf{2 4 5}$ & $\mathbf{1 0 0 . 0}$ & \\
\hline
\end{tabular}

Table 10 shows monthly family income, maximum $39.6 \%$ had monthly income $>5000-10000$ taka, followed by $29.8 \%$ had monthly income $>10000-15000$ taka, $16.7 \%$ had monthly income $>15000$ taka and $13.9 \%$ had monthly income $3000-<5000$ taka. The average income was 123265541 taka.

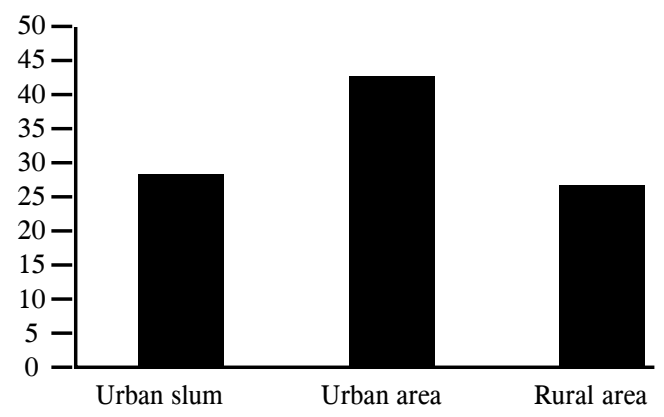

Fig. 1: Residential status of the patients
Fig. 1 shows the distribution pattern of the respondents as per their dwelling status. Highest proportions of respondents (44\%) were from the urban areas, and about $28 \%$ respondents are from rural areas. However, about $29 \%$ of the respondents are from the urban slum which clearly shows that, they need the services more necessarily. On the other hand mothers of urban area were found likely to be had good nutritional status and less anemic during pregnancy.

\section{Discussion}

In country like Bangladesh, pregnant women represent the most vulnerable to nutritional deprivation. Severe anaemia has been suggested to be associated with a high risk of maternal mortality. ${ }^{13}$ Malnutrition rates have seen a marked decline in Bangladesh throughout the 1990s, but remained high at the turn of the decade. ${ }^{12}$ Case of anaemia still high in pregnant women has low consciousness about the importance of anaemia prevention and the danger of less iron supplement. ${ }^{11}$

In our study, proportion of women with optimum height (more than 5 feet) constituted about $40 \%$ of the total women which indicates that majority of the women (about 60\%) suffered from chronic energy deficiency as indicated by their low stature / height. Similar kind of study conducted at Thailand Christopher et al found prevalence of iron deficiency anaemia and vitamin A deficiency were $15.1 \%$ among pregnant women in northeast Thailand. ${ }^{16}$

The mean weight of women was about $49 \mathrm{~kg}$, weight of $61 \%$ women less than $50 \mathrm{~kg}$ while they were pregnant (with different trimester). Although weight of about $40 \%$ women was more than $50 \mathrm{~kg}$, still majority of the pregnant women were less than $50 \mathrm{~kg}$. This findings is similar to the thesis result of Farhana Haseen, she found that one third of women were found chronically malnourished (height $<145 \mathrm{~cm}$. According to BMI $\left(<18.5 \mathrm{~kg} / \mathrm{m}^{2}\right)$ more than half of women were chronic energy deficient. Among these energy deficient women, $14 \%$ were severely energy deficient $(<16.0 \mathrm{~kg} / \mathrm{m} 2)$. Anemia was found in about half of the women of study population. ${ }^{15}$

In our study we found $42.04 \%$ women had normal BMI, where $20 \%(<18.5)$ were underweight, $30.20 \%$ overweight (25-29.9), and 8\% were obese $(>30)$. In a study on pregnant women Sohana et al. found around $43 \%$ women have normal BMI which has a clear relationship with their socio-economic status. ${ }^{14}$

Our findings reveal that majority of the pregnant women suffered from chronic energy deficiency (CED) as indicated by low weight even during 
pregnancy. In the 1 st trimester, there were only 48 women and $42.5 \%$ of them were less than $40 \mathrm{~kg}$ where as in 2 nd and $3^{\text {rd }}$ trimester, number of the pregnant women with more than $40 \mathrm{~kg}$ and more than $50 \mathrm{~kg}$ increased significantly. The number of pregnant women in the $2^{\text {nd }}$ and $3^{\text {rd }}$ trimester was 118 and 79 percent respectively, and body weight $40 \mathrm{~kg}$ was more in $1^{\text {st }}$ trimester than $2^{\text {nd }}$ and $3^{\text {rd }}$ trimester which was $42.5 \%$ vs. $35 \%$ and $22.5 \%$. Sohana et al., found that the prevalence of chronic energy deficiency [CED, body mass index $(\mathrm{BMI})<18.5 \mathrm{~kg} / \mathrm{m}^{2}$ ] continues to be major nutritional problem among Bangladeshi women.

In our study, out of 245 respondents, 103 of them were normal in all the trimesters of pregnancy. It is surprising that $93(38 \%)$ of them were either over weight or obese which is much higher than the percentage of women who put on weight that is more than $07 \mathrm{~kg}$ and above. This data set shows that a significant proportion of pregnant women put additional weight which is detrimental for the overall outcomes of the pregnancy.

\section{Conclusion}

We know that there is a strong relationship between weight gain during pregnancy and weight of the baby at the womb. It is important to note that in our country, majority of babies do born with low birth weight. Pregnant women are suffering from chronic deficiency anemia which resulted with pregnancy related complications. Mass motivational activities should be in the mass media particularly on proper weight during pregnancy to have better pregnancy outcome. However, our study has some limitations like short duration and lack of representativeness of samples. Further studies on this issue should be conducted to assess the anthropometric condition of pregnant women.

\section{Conflict of interest : None.}

\section{Reference}

1. Reddy S, Sanders TAB. Hematological studies on premenopausal Indian and Caucasian vegetarians compared with Caucasian omnivores, Br J Nutr 1990; 64: 331-38.

2. Antal M, Regoly-Merei A, Varsanyi H, et al. Nutritional Survey of pregnant women in Hungary. Intetnat J Vit Nutr Res 1997; 67: 115-22.

3. Blaxter M, Evidence on inequality in health from a national survey. Lancet 1987; ii: 30-3.
4. Feldman JJ, Makuc DM, Kleinman JC, et al. National trends on educational differentials in mortality. Am $\mathrm{J}$ Epidemiol 1989; 129: 919-33.

5. Guigoz Y, Vellas B, Garry PJ. Assessing the nutritional status of the elderly: the mini nutritional assessment as part of the geriatric evaluation. Nutr Rev 1996; 54:59-65.

6. Tanner J, Hiernaux J, Jarman S. Growth and physique studies. In: Weiner J, Lourie J, eds. Human biology: a guide to field methods. IBP Handbook no 9. oxford: Blackwell, 1969.

7. Bergner L, Susser MW. Low birth weight and prenatal nutrition: an interpretative review. Pediatrics 1970; 46: 94676.

8. Falkner F. Key issues in infant mortality. J Trop Pediatr 1971; 17:3-6.

9. Brasel JA, Winick M. Maternal nutrition and prenatal growth. Arch Dis Child 1972; 47: 479-82.

10. Osofsky HJ. Relationship between nutrition during pregnancy and subsequent infant and child development. Obstet Gynecol Surv 1975; 30: 227-41.

11. A.G.M., E. Schouten., Y. Wang., R.X. Xu., M.C. Zheng., Y.Li., Y.Y. Sun., Q.Z. Wang. Anemia Prevalence among Pregnant Women and Birth Weight in Five Areas in China. Med Prince Prac 2009; 18: 368-372.

12. h t t p : / / w w w . un ice f . or g/ banglade s h / Child_and_Maternal_Nutrition\%281\%29.pdf accessed on 18 April, 2014

13. Jackson DJ, Klee EB, Green SD, et al. Severe anaemia in pregnancy: a problem of primigravidae in rural Zaire. Trans. R. Soc. Trop. Med. Hyg. 1991; 85: 829 \pm 32

14. Trends of under- and overweight among rural and urban poor women indicate the double burden of malnutrition in Bangladesh Sohana Shafique, Nasima Akhter,Gudrun Stallkamp,Saskia de Pee,Dora Panagides and Martin W Bloem. International Journal of Epidemiology 2007; 36: 449-457

15. Malnutrition among Bangladeshi women in ultra poor households: prevalence and determinants. Farhana Haseen MS Thesis, Department of Women's and Children's Health, Uppsala University

16. Nutritional status of pregnant women in Northeast Thailand Christoph U Andert, Pattara Sanchaisuriya PhD , Kanokwan Sanchaisuriya $\mathrm{PhD}$,Frank $\mathrm{P}$ Schelp $\mathrm{PhD}$ and Florian J Schweigert PhD. Asia Pac J Clin Nutr 2006;15 (3): 329-334 